\title{
Variáveis relativas a eficiência energética em estações elevatórias de água
}

Variables related to energy efficiency in water pumping stations.

Las variables relacionadas con la eficiencia energética en las estaciones de bombeo de agua.

Oswaldo Buzolin Junior Doutorando em Recursos Hídricos, UNICAMP, Brasil. jobuzolin@gmail.com

\section{Paulo Sérgio Franco Barbosa}

Professor Doutor, UNICAMP, Brasil. franco@fec.unicamp.br

Victor de Barros Deantoni Doutorando em Recursos Hídricos, UNICAMP, Brasil. vbdeantoni@gmail.com 


\section{RESUMO}

Atualmente além do uso racional dos recursos hídricos é preciso atuar na sua redução considerando os elevados custos, principalmente com energia elétrica. A busca de pela eficiência energética nas estações elevatórias se torna algo imprescindível para uma boa gestão, que objetiva redução de despesas sem redução da produtividade. Parâmetros de observação para gestão de uma empresa, são na atualidade algo imprescindível para uma administração eficiente, podem permitir que o gestor tenha percepção de onde e como atuar com melhores perspectivas de retorno. Além disso pode ajudar os órgãos reguladores na avaliação da gestão. Nas empresas de abastecimento de água, considerando: a complexidade dos sistemas de captação de água bruta nos mananciais, e as complexas redes de distribuição de água tratada; o expressivo consumo de energia elétrica, que representa significativa parcela das despesas da empresa, em alguns casos perdendo somente para a folha de pagamento dos funcionários; a redução gradativa do desconto das tarifas que o governo tem dado para esse insumo; e também pelas sucessivas altas nas tarifas de energia elétrica, que tem, na maioria das vezes, superado a inflação. Ter informações relativas à eficiência energética, na qual situe o gestor em relação ao que pode ser melhorado para reduzir os custos de energia elétrica na empresa, torna-se algo de extrema importância, além de contribuir para gerir de forma a considerar a eficiência energética.

PALAVRAS-CHAVE: Energia Elétrica. Eficiência Energética. Sistemas de Abastecimento de Água.

\section{RESUMO EM INGLÊS}

Nowadays, in addition to the rational use of water resources, it's necessary to act in reducing its high costs, especially the ones involved with electricity. The search for energy efficiency in pumping stations becomes something essential to good management, which aims to reduce costs without reducing productivity. Parameters of observation are essential to good management, allowing the manager to identify the areas with the best perspectives of return, in addition to assisting the regulatory organizations during their management evaluations. In water supply companies, taking into consideration: the complexity of raw water collection systems in watersheds, and the complex distribution networks of treated water; the significant energy consumption, which represents a significant portion of a company's costs, only being smaller than a company's payroll in some cases; the gradual reduction of the discount given by the government over the electricity rates; and also by the successive increases in electricity rates, which have, in most cases, surpassed inflation. Having information on energy efficiency is very important, because it allows the manager to know what can be improved in order to reduce a company's energy costs, in addition to contributing to the management when considering energy efficiency.

KEYWORDS: Electricity. Energy Efficiency. Water Supply Systems.

\section{RESUMO EM ESPANHOL}

Actualmente, además, a la utilización racional de los recursos hídricos es necesario actuar en la reducción teniendo en cuenta los altos costos de la electricidad. La búsqueda de la eficiencia energética en las estaciones de bombeo se convierte en algo esencial para la buena gestión, cuyo objetivo es reducir los costes sin reducir la productividad. Los parámetros de observación, son esenciales para la gestión de una empresa de manera eficiente. Esto puede permitir que el administrador tiene la percepción de dónde y cómo actuar con mejores perspectivas de rendimiento. Esta gestión también puede ayudar a los responsables de la regulación en la evaluación de la gestión. En las empresas de suministro de agua, teniendo en cuenta: la complejidad de los sistemas de captación de agua cruda en la cuenca, y las redes de distribución de agua tratada complejos; el consumo significativo de electricidad, lo que representa una porción significativa de los costos de la empresa, en algunos casos, sólo los empleados de nómina es más grande; la reducción gradual de las tarifas de descuento que el gobierno ha dado a esta entrada; y también por los sucesivos incrementos en las tarifas eléctricas, que tienen, en la mayoría de los casos, superar la inflación. Tener información sobre la eficiencia energética permite al gestor de saber qué se puede mejorar para reducir los costos de energía en la empresa es muy importante, además de contribuir para gestionar teniendo en cuenta la eficiencia energética

PALABRAS CLAVE: Electricidad. Eficiencia energetica. Suministro de agua. 


\section{INTRODUÇÃO}

O fornecimento de energia elétrica à população tem sido uma preocupação não somente no Brasil, mas em muitos outros países principalmente diante do crescente aumento na demanda devido à tendência de universalização do serviço e do crescente surgimento de eletro intensivos. Para atender a essa demanda têm surgido várias propostas e ideias com o intuito de incrementar as formas de se obter energia elétrica com métodos alternativos que também minimizem o impacto ao meio ambiente como, por exemplo: a geração de energia através da força dos ventos, da energia solar e até da oscilação das marés. $O$ uso racional e eficiente da energia elétrica também é uma frente que certamente contribuirá muito para o contínuo atendimento à demanda. Devido aos altos custos para novos aproveitamentos energéticos somados ao aumento do consumo, e de políticas instáveis para o setor, o custo da energia elétrica no Brasil tem sido cada vez mais elevado, obrigando os consumidores a encontrar novas formas de promover o uso eficaz da energia elétrica. A política de conservação de energia vem a cada dia ganhando importância no cenário mundial, buscando junto à população o uso eficiente da energia elétrica, ou seja, conseguir os melhores resultados na relação entre a quantidade de energia consumida, por determinado equipamento ou aparelho em operação, e a quantidade de energia efetivamente utilizada pelo mesmo para realizar a tarefa a que se propõem.

Outro setor que requer atenção é o de saneamento onde o abastecimento de água potável, além de garantir a qualidade de vida, também atende às questões de saúde pública. Neste contexto, CARVALHO, 2006, relata que alguns anos atrás a prioridade era simplesmente abastecer a população com água em quantidade e com qualidade. Atualmente as exigências são bem maiores, pois além de atender a estes princípios básicos, os sistemas passaram a se preocupar ainda com a escassez dos recursos hídricos, e também com as elevadas tarifas de energia elétrica. Hoje, os sistemas devem se adaptar às novas exigências, pois caso contrário com o tempo poderão sofrer interrupções no abastecimento devido a ineficiência.

Em grande parte do mundo, nos setores de abastecimento de água e de esgotamento sanitário ocorrem perdas significativas tanto de água bruta ou tratada, como de energia elétrica, que são relativas à sua gestão. As perdas físicas de água ocorrem desde a captação de água até a distribuição nas ligações prediais, as quais acabam se traduzindo também em perda de energia. Conforme dados do SNIS, 2014, as perdas físicas de água na distribuição dos sistemas de abastecimento de água no Brasil variam de $25 \%$, a quase $80 \%$ em algumas cidades do país. Porém esse problema não é exclusivo do Brasil e ocorre em vários países do mundo conforme menciona LAMBERT, 2001. As perdas de energia elétrica também são elevadas tanto quanto as perdas de água, e ocorrem principalmente nas estações elevatórias de água bruta e tratada, bem como, nas estações elevatórias de efluentes. Essas perdas ocorrem principalmente devido à baixa eficiência dos equipamentos, como os conjuntos motor e bomba de recalque, por equipamentos obsoletos, por procedimentos operacionais inadequados, por falta de manutenção e por projetos que não atendam a critérios de eficiência energética. De acordo com JAMES et AL., 2002, os sistemas de distribuição de água no mundo consomem sete por cento de toda energia elétrica gerada. De acordo com o Programa Nacional de Conservação de Energia Elétrica para o Saneamento - PROCEL, 2014, 2,36 \% do consumo total de energia elétrica do Brasil, o equivalente a 11,35 bilhões de kWh/ano, é consumido pelas empresas de abastecimento de água e coleta e tratamento de efluentes. Este consumo é 
principalmente dos conjuntos eletromecânicos dos processos de abastecimento de água e de esgotamento sanitário, que correspondem algo em torno de noventa por cento de toda a despesa com energia elétrica.

No Brasil, nos últimos anos, os investimentos no setor energético se revelam críticos, motivo pelo qual se torna de suma importância a implementação de políticas visando o uso racional da energia. Com esse objetivo, foram criados em 1983, a Agência para Aplicação de Energia e em 1993, o Programa Estadual de Racionalização do Uso de Energia Elétrica, no Estado de São Paulo e, a nível federal, em 1985 o Programa de Conservação de Energia Elétrica - PROCEL. Devido à privatização das concessionárias de energia elétrica no Estado de São Paulo, a Agência para Aplicação de Energia foi extinta, surgindo em 1995 o Programa de Combate ao Desperdício de Energia Elétrica que alterou o Programa de Conservação de Energia Elétrico criado pela Eletrobrás em 1985. Para o Setor de Saneamento Básico, somente em 1997, o PROCEL estabeleceu uma meta de redução de $15 \%$ no desperdício de energia elétrica.

Em 1999 a PROCEL estabeleceu as principais ações para o setor de Saneamento Básico como:

- Automação operacional de sistemas com gerenciamento e supervisão instantânea dos equipamentos;

- Modulação de carga em relação à ponta dos sistemas elétricos;

- Dimensionamento adequado dos equipamentos eletromecânicos;

- Controle das vazões de recalque em relação às demandas da rede de distribuição de água;

Através da resolução n²42 de 24 de julho de 1998, a Agência Nacional de Energia Elétrica- ANEEL, atualmente responsável pela legislação e fiscalização do setor elétrico nacional, estabeleceu que as concessionárias do serviço público de distribuição de energia elétrica, devem aplicar anualmente, no mínimo, $1 \%$ da receita operacional anual apurada no ano anterior, em programas para conservação de energia elétrica, sendo que $25 \%$ deste valor devem ser aplicados para consumidores.

Conforme relata TSUTIYA, 2006, para a SABESP, no ano de 1977, a energia elétrica tinha um custo relativo a quatro por cento do total das despesas. Considerando que, para o fornecimento de mil litros de água o consumo de energia elétrica se mantenha em torno de 0,6 kWh, em 1988 as despesas aumentaram para doze por cento, de forma que, o custo da energia elétrica passou a ser o terceiro maior no orçamento da empresa, nessa linha surgem ferramentas de otimização conforme demonstra FRANCATO at al., 2011, que minimizam os custos com energia elétrica na operação dos sistemas. É estimado que no mínimo noventa por cento dos custos são devidos às estações elevatórias de água (TSUTIYA, 1989). Para os anos, 1995 a 1999, o custo de energia elétrica na SABESP esteve em torno de oito por cento das despesas. Dentre as indústrias no Estado de São Paulo, a SABESP tem sido a maior empresa consumidora de energia elétrica, com um consumo em torno de três por cento de toda a energia consumida no Estado de São Paulo.

Para HAGUIUDA, SANTOS NETTO e COURA, 1996, os sistemas operados pela SABESP na Região Metropolitana de São Paulo, consomem 90\% de toda a energia com motores, 7,5\% com serviços auxiliares e 2,5\% com iluminação.

Considerando a grandiosidade dos números relativos às despesas com a energia elétrica consumida nas estações elevatórias das empresas de saneamento, torna-se importante mensurar a eficiência energética desses sistemas. Isso posto, conhecer as variáveis envolvidas na avaliação da eficiência energética, bem como a composição de índices de desempenho energético para as estações elevatórias de água, auxiliam a empresa na análise do consumo racional de energia elétrica. 


\section{OBJETIVOS}

O objetivo do trabalho é estudar as variáveis relativas às estações elevatórias de água, que refletem no consumo de energia elétrica e consequentemente nos custos, observando os elementos constituintes dos sistemas de abastecimento urbano de água, os quais têm reflexos na captação de água bruta, adução, armazenamento e distribuição.

Com a identificação das variáveis mais significativas para a avaliação da eficiência energética, baseado em referências bibliográficas que indicam a experiência brasileira sobre desempenho aplicável ao setor de saneamento. Pretende-se com a análise dessas variáveis que se tenham as seguintes utilidades para as entidades envolvidas com os sistemas de abastecimento de água:

- Fornecer informações de desempenho que constitua um instrumento de apoio à gestão das entidades administradoras de sistemas de abastecimento de água;

- Ampliação da base de análise comparativa, a qual trará melhores subsídios à gestão energética dos sistemas de abastecimento de água;

\section{REVISÃO BIBLIOGRÁFICA}

\section{Sistema de Abastecimento de Água}

Com o crescimento das cidades e consequentemente da população, tornou-se cada vez mais necessário captar água em maior quantidade e distância dos pontos de consumo, o que levou as empresas de abastecimento de água a construir sistemas de captação de água, na maioria das vezes em mais de um manancial, considerando o crescente consumo de água pela população, a construir linhas de adução que cruzam grandes distâncias levando água do manancial até as cidades, executar estações de tratamento de água com estrutura e técnicas para tratar a água a partir da qualidade da água captada, reservatórios para o armazenamento da produção de água e redes de distribuição para levar água até as torneiras das residências, comércios, indústrias, hospitais, prédios públicos e outros locais onde haja necessidade de água com qualidade e quantidade desejável. E como consequência a utilização de energia elétrica para pôr em funcionamento todas essas estruturas do sistema abastecimento de água, é cada vez maior, com os custos crescentes, além de ser preocupante do ponto de vista de disponibilidade de energia elétrica. Segundo SÁ (2010) os custos típicos de uma estação de bombeamento durante sua vida útil são de $5 \%$ relativo à instalação, $10 \%$ relativo a manutenção e $85 \%$ para os custos de energia elétrica para operação de sistemas elevatórios.

\section{HISTÓRICOS DOS SISTEMAS DE ABASTECIMENTO DE ÁGUA}

Devido ao crescimento desordenado e descontrolado dos centros urbanos, para o atendimento do abastecimento de água gerou-se uma grande complexidade operacional nos SAA, obrigando as empresas de abastecimento de água a ampliarem suas estruturas para atender as mais variadas condições de demanda geradas pelas distâncias e topografias adversas (ZESSLER e SHAMIR, 1989). 
Isso posto, as estações elevatórias de água bruta e água tratada tem que ser inseridas nos sistemas operacionais de distribuição de água para o atendimento pleno dos mais longínquos consumidores com pressão e vazão adequados para o fornecimento de água.

A dificuldade investimentos no setor energético nas últimas décadas levou este sistema a uma situação crítica, o que culminou em medidas que foram desde a criação do Programa de Conservação de Energia Elétrica - PROCEL em 1985, depois denominado para Programa de Combate ao Desperdício de Energia Elétrica em 1995, até a elevação do custo da energia elétrica. Custo esse que era subsidiado nas décadas de 60 e 70, onde em 1968 atingiu um índice de 80\% de subsídio nas tarifas de energia elétrica para as empresas de saneamento. A partir dos anos 90 , houve uma redução gradativa desse subsídio até atingir os atuais 15\%. A figura 1 ilustra o gráfico relativo à redução do desconto da tarifa de energia elétrica para o setor de saneamento para as empresas CESP e ELETROPAULO.

Segundo TSUTIYA, 2006, a partir de 1.997 o PROCEL estabeleceu uma meta de redução do desperdício de energia elétrica para as empresas de saneamento da ordem de $15 \%$.

Figura 1: Gráfico relativo à redução do desconto da tarifa de energia elétrica para o setor de saneamento para as empresas CESP e ELETROPAULO

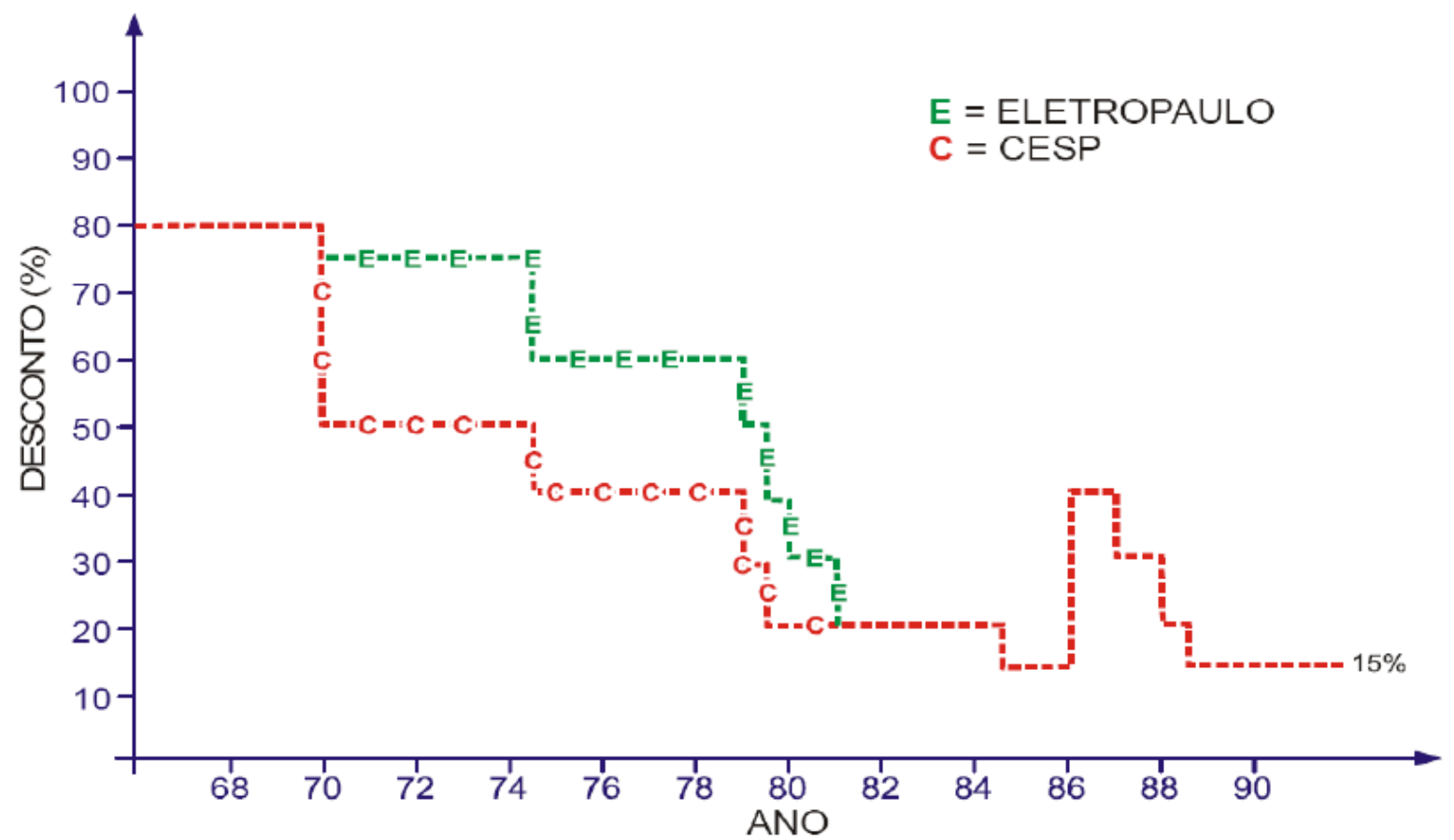

Fonte: CASSIANO FILHO e TSUTIYA, 1992.

Em 1996 é criada a Agencia Nacional de Energia Elétrica - ANEEL, a qual passou a ser responsável pela legislação e fiscalização do setor elétrico nacional. Prevendo o risco de racionamento de energia elétrica, a ANEEL impõem entre outros atos a Resolução número 242 de 24/07/98, que estabelece que as concessionárias do serviço público de distribuição de energia elétrica teriam que aplicar no mínimo $1 \%$ da receita operacional anual do ano anterior em programas de conservação de energia elétrica. Apesar da tentativa, não foi suficiente para evitar o pior e no mesmo ano de 2000, já haviam previsões pessimistas para o setor energético cuja possibilidade de um racionamento somente seria 
evitado se as chuvas e os níveis operacionais dos reservatórios das usinas hidroelétricas inseridas no SIN - Sistema Interligado Nacional voltassem a recuperar os seus níveis para patamares satisfatórios conforme relata AMIGO, 2000. Conforme relatos do mesmo autor, o Ministério das Minas e Energia estava tratando nesse período de uma redução do consumo junto aos grandes consumidores, numa tentativa de gerenciamento de demandas, denotando a situação crítica em que o Brasil estava atravessando. Apesar da iniciativa, a crise do setor energético foi inevitável e culminou no racionamento de energia elétrica ocorrido em 2001. Graças às chuvas ocorridas em 2002 o sistema se reestabeleceu, mas expos a fragilidade do sistema de geração de energia elétrica no Brasil. Baseado na Lei número 10.438 de 26/04/2002, a ANEEL no dia 28/06/2002 cria um novo encargo, as tarifas, denominada de Encargo de Capacidade Emergencial - ECE, a um custo fixo de R\$ 0,0035/kWh (Base: Julho/2.005) para todos os tipos de consumidores, cujo objetivo era o financiamento de obras de expansão do sistema de geração de energia elétrica, incidindo diretamente na composição global da conta. A constitucionalidade desse encargo foi discutida na esfera jurídica, porém, segundo CARVALHO, 2006, o Supremo Tribunal Federal - STF de maneira inexplicável decidiu pela constitucionalidade do mesmo, onde a cobrança foi aplicada até o ano de 2006.

\section{HISTÓRICO DO SETOR DE ENERGIA ELÉTRICA BRASILEIRO}

No século XVIII o americano Benjamin Franklin (1.706 - 1.790) apresentou as primeiras citações e experiência com a energia elétrica, na sequência Thomas Alva Edison (1847-1931) inventou no ano de 1879 a lâmpada elétrica incandescente que podia ser comercializada, logo em 1891 foram fabricados os primeiros motores assíncronos. A partir desses desenvolvimentos consolidou-se com o tempo e o domínio desta fonte de energia, uma grande revolução nos processos industriais onde no passado a energia utilizada para alimentar as máquinas era o vapor gerado a partir da queima de materiais fosseis como carvão ou madeira, e passou de forma definitiva a ser utilizada a energia elétrica.

Considerando o grande desenvolvimento industrial e populacional, para suprir a grande demanda de energia elétrica surgiram várias alternativas de geração de energia elétrica como: hidráulica, térmica, nuclear, solar e eólica, além de alternativas que ainda estão em fase de estudos e desenvolvimento.

A maior parte da eletricidade utilizada em países industrializados tem seu consumo associado a motores elétricos conforme relata ALMEIDA et aL, 2003 e 2005. Ainda segundo o autor, sistemas de motores são responsáveis por $69 \%$ da eletricidade consumida nos setores da indústria, e $38 \%$ no setor de serviços na União Europeia. Com estimativa média de uma taxa de crescimento anual do consumo de energia elétrica até o ano de 2015 de 1,2\% e 1\% para ambos os setores.

No Brasil esses índices se apresentam de forma parecida. Conforme OLIVEIRA JR., 1993, 40\% do consumo dos motores elétricos industriais se destinam ao manuseio de fluídos, o que representava à época, quase $30 \%$ de todo consumo industrial de energia elétrica. AMIGO, 2000 apresenta através de dados do PROCEL de 1999, que o setor industrial do país era o responsável sozinho por $45 \%$ do consumo de energia do país e, desse total, $51 \%$ se destinavam ao consumo de motores elétricos. Dados mais atuais disponíveis no Balanço Energético Nacional - BEN, 2015 referente ao ano base de 2014, mostram a participação industrial já num valor de $38,80 \%$ do total da eletricidade consumida no país e se mantendo praticamente o mesmo percentual destinado ao consumo de energia elétrica para sistemas motrizes. De acordo ainda com dados do Balanço Energético Nacional - BEN, 2015 
referente ao ano base de 2014, somente o uso de eletricidade representou 45,65 milhões de TEP Tonelada Equivalente de Petróleo, ou 18,27\% de toda a energia final consumida no país.

\section{Indicadores de Gestão de Desempenho em Empresas de Abastecimento de Água}

$\mathrm{Na}$ busca dos objetivos de gestão, as empresas de saneamento estão sempre à procura de incrementar os padrões de eficiência e de eficácia, onde: A eficiência mede até que ponto os recursos disponíveis são utilizados de modo otimizado para a produção do serviço; A eficácia mede até que ponto os objetivos de gestão, definidos específica e realisticamente, foram cumpridos.

Diante do grande número de informações existentes nos sistemas de abastecimento de água fica difícil e às vezes até inviável avaliar a eficiência e a eficácia da empresa, ou então, se comparar às outras empresas com condições de topografia, padrão de consumo e tipos de consumidores diferentes. Os indicadores de desempenho (ID) constituem uma ferramenta de uso comum em muitos setores da indústria em todo o mundo, sendo que as suas potencialidades são inquestionáveis nas empresas de abastecimento de água.

Um indicador de desempenho é uma medida quantitativa de um aspecto particular do desempenho de uma empresa responsável pela gestão ou do seu nível de serviço. É um instrumento de apoio ao monitoramento da eficiência e da eficácia da entidade gestora, simplificando uma avaliação que de outro modo seria mais complexa e subjetiva.

De acordo com ALEGRE et al, 2006, considerando as relações entre agentes envolvidos e recursos utilizados, é possível identificar cinco tipos de objetivos de gestão:

- Proporcionar aos consumidores um nível de serviço apropriado, cumprindo políticas nacionais e regionais, requisitos estatutários ou outras obrigações;

- Atingir elevada produtividade dos recursos humanos, porém dando condições e oportunidades de valorização profissional e de carreira, de acordo com as qualidades e as aptidões de cada um;

- Maximizar a eficiência do uso dos recursos hídricos, energéticos e ambientais;

- Dar garantia de uma elevada eficiência na aplicação dos recursos financeiros;

- Planejar, construir, operar e manter as infraestruturas de forma eficaz e eficiente.

\section{Perdas de Energia Elétrica nos Sistemas de Abastecimento de Água}

A grande preocupação das empresas de abastecimento de água sempre foram as perdas físicas e financeiras de água, entretanto, com o aumento do custo da energia elétrica, a redução dos subsídios e com a evolução tecnológica dos motores e equipamentos de automação, as perdas de energia elétrica, assim como as perdas de água passaram a ganhar importância, e ser objeto de estudo e análise com o objetivo principal da redução de custos.

TSUTIYA, 2006 menciona em seu trabalho que se é possível reduzir as despesas com energia elétrica em uma empresa de abastecimento de água de duas maneiras basicamente:

- Redução do custo sem diminuição do consumo de energia elétrica;

- Redução do custo com diminuição do consumo de energia elétrica. 


\section{Redução dos Custos de Energia Elétrica Sem a Diminuição do Consumo}

Devido à complexidade da estrutura tarifária de energia elétrica praticada no Brasil, e muitas vezes da falta de profissionais capacitados e empenhados em verificar as contas e os contratos do fornecimento de energia elétrica, principalmente em sistemas de abastecimento de água de pequeno porte e gerido pela administração pública, muito se perde financeiramente com o consumo de energia.

Na sequência apresenta-se alguns itens a serem observados com relação as contas de energia elétrica consumida pelos equipamentos das empresas de saneamento básico:

- Classificação da unidade consumidora como empresa de saneamento para gozar do desconto de $15 \%$ na tarifa de energia elétrica;

- Ajuste na demanda contratada de acordo com os equipamentos em operação;

- Alteração da estrutura tarifária de acordo com o perfil de consumo;

- Desativação de unidades consumidoras inoperantes;

- Verificação de eventuais erros de Leitura;

- Correção do Fator de Potência das instalações caso seja inferior a 0,92;

- Dimensionamento correto de motores para os conjuntos;

- Dimensionamento adequado de transformadores para a demanda;

- Nível de tensão acima da nominal;

- Alteração da tensão de alimentação de baixa para alta tensão, quando possível;

- Melhoria do fator de carga, com a seleção de motores de menor potência que conseguem realizar o trabalho ao longo do dia;

\section{Redução dos Custos de Energia Elétrica Com a Diminuição do Consumo}

Segundo TSUTIYA, 2006, o consumo de energia elétrica de uma estação elevatória de água pode ser calculado pela expressão:

$$
E=0,00273 \frac{H * V}{n}
$$

onde:

$\mathrm{E}$ - Energia consumida em kWh;

$\mathrm{H}$ - Altura manométrica de bombeamento em $\mathrm{m}$;

$\mathrm{V}$ - Volume de água bombeada $\mathrm{em}^{3}$;

$\mathrm{n}$ - rendimento dos conjuntos motor-bomba.

Conforme se observa na expressão anterior, para a redução do consumo de energia e consequentemente dos custos com energia elétrica é necessário reduzir a altura manométrica ou o volume bombeado, assim como aumentar o rendimento dos conjuntos motor-bomba. Ou qualquer variável que esteja relacionada as variáveis da formula 3.3. Na sequência seguem algumas formas de reduzir o consumo de energia elétrica: 
- Redução da altura manométrica;

- Diâmetro adequado da tubulação para o recalque;

- Elaboração de projetos de estações elevatórias de água observando sempre a eficiência dos equipamentos das instalações;

- Redução do atrito da parede interna da tubulação com a água e consequentemente da altura manométrica;

- Eliminação do ar no interior das tubulações

- Perda físicas de água no sistema de abastecimento de água;

- Mistura de setores de abastecimento de água;

- Uso racional da água;

- Aumento do rendimento dos conjuntos motobomba;

- Redução dos custos de energia elétrica pela a alteração da operação do sistema;

- Ampliação da reservação de água;

- Utilização de inversores de frequência nos conjuntos motobomba;

\section{METODOLOGIA}

As principais unidades consumidoras de energia elétrica em uma empresa de abastecimento de água são as estações elevatórias de água. Logo as observações e estudos, devem ser desenvolvidos com foco nessas unidades e consequentemente nas variáveis relativas às operações de recalque de água, as quais são interessantes para o auxílio na busca da eficiência energética.

Numa estação elevatória de água, onde o auxílio dos equipamentos eletromecânicos transforma a energia elétrica em trabalho, mais especificamente em vazão, pretende-se analisar as principais variáveis envolvidas com as tubulações, os motores, as bombas, os conjuntos, as operações, e os custos.

A Figura 2 ilustra um esquema com as principais variáveis relativas à eficiência energética presentes numa estação elevatória de água. 
Figura 2 - Variáveis relativas à eficiência energética de uma estação elevatória de água.

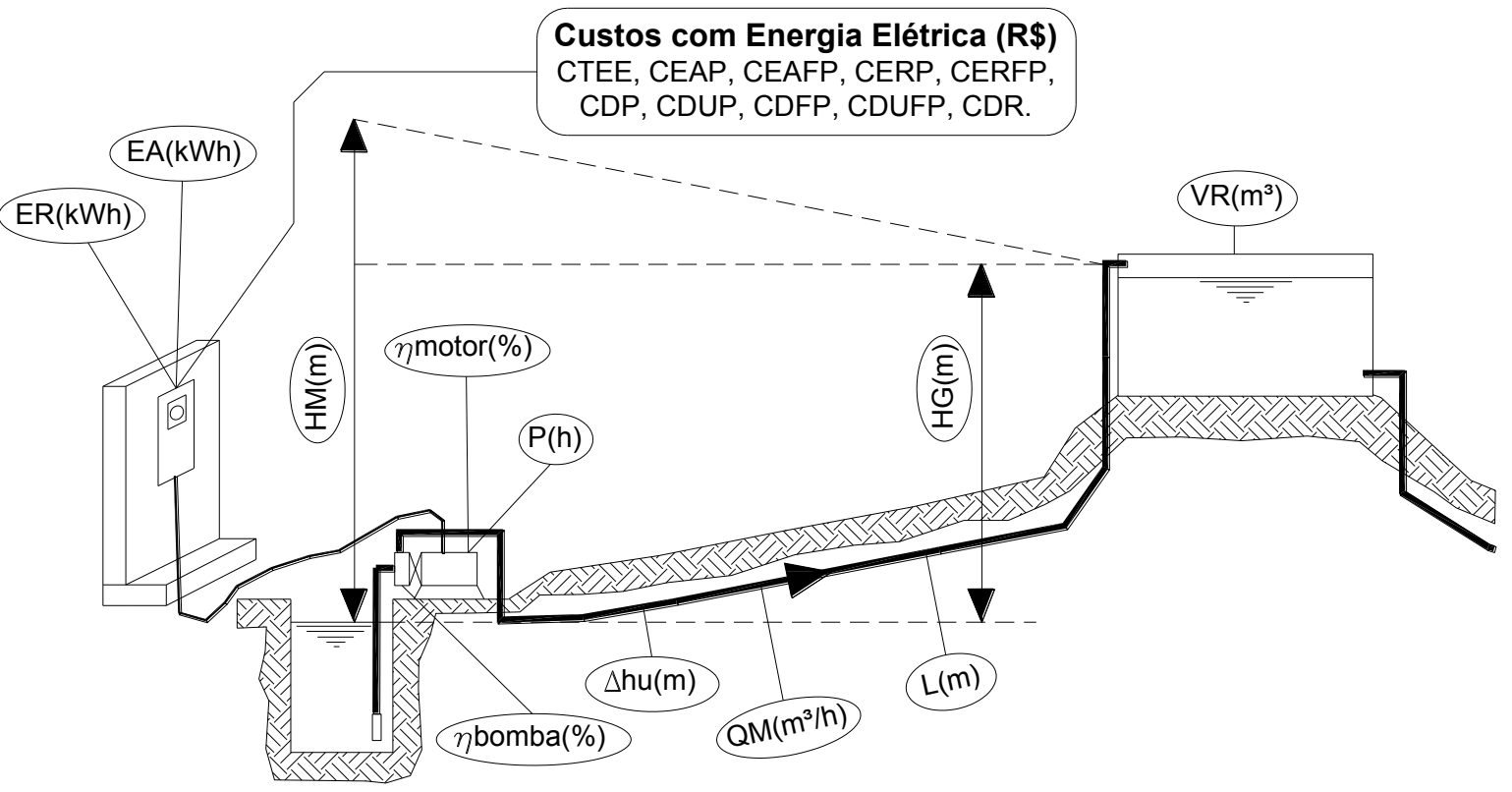

Fonte: Autor

As principais variáveis são:

- EA - Energia ativa consumida em kWh, expressa o consumo efetivo de energia elétrica dos motores das estações elevatórias e das demais instalações para realizar o recalque, nessa variável os custos da energia não é considerado;

- ER - Energia reativa gerada em $\mathrm{kWh}$, expressa a quantidade de energia reativa gerada pelos motores das estações elevatórias e das demais equipamentos para realizar o recalque;

- HG - Altura geométrica do recalque de água da estação elevatória em metros. Trata-se do desnível do ponto a montante de menor cota altimétrica para o ponto a jusante de maior cota. Em resumo é altura a ser vencida pelo conjunto motobomba com a vazão necessária para suprir a demanda;

- HM - Altura manométrica do recalque em metros, relativo a carga necessária para recalcar a água do ponto de menor cota altimétrica para o ponto a jusante de maior cota, considerando as perdas de carga relativas a rugosidade da tubulação e a resistência das singularidades como conexões, válvulas e redução de diâmetro;

- L L Extensão da tubulação em metros, desde a sucção até o final da tubulação;

- $\Delta$ hu - Perda de carga unitária na tubulação. A relação entre a perda de carga (HM-HG) e extensão da tubulação desde a sucção até o destino final, independente do diâmetro da tubulação. $O$ valor é expresso em metros por metros.

- P - Período de funcionamento dos conjuntos motor e bomba em horas. Compreende o tempo de operação da estação elevatória durante um dia;

- $\mathbf{Q M}$ - Vazão média em $\mathrm{m}^{3} / \mathrm{h}$. É o volume de água recalcada divido pelo período de funcionamento das bombas. A vazão média pode ser obtida através do volume de água 
recalcada dividido pelo tempo, ou com o auxílio de equipamentos precisos de medição de vazão, os quais registram os valores instantâneos e geram o valor médio;

- VR - Volume recalcado em metros cúbicos. Volume total de água recalcada em 24 horas. Com o auxílio do macro medidor é possível obter essa informação, porém caso a leitura for feita manualmente, é imprescindível que seja elaborada sistematicamente no mesmo horário todos os dias para se evitar distorções nos valores medidos;

- $\eta_{\text {Motor }}$ - Rendimento do motor do conjunto de recalque, obtido com a medição da potência (Kwh), da tensão (V) e da amperagem (A) consumida para o funcionamento, bem como do conjugado $(\mathrm{Kgfm})$ com o auxílio do torquímetro e da rotação (RPM) do motor com o tacógrafo;

- $\eta_{\text {Bomba }}$ - Rendimento da bomba responsável pelo recalque de água. Com a potência elétrica consumida pelo motor, o rendimento do motor, altura manométrica, vazão e peso específico da água, é possível se determinar o rendimento da bomba.

- CTEE - Custo total de energia elétrica em Reais. Refere-se ao custo de energia elétrica gasta para realizar o trabalho a que se propõem. O custo inclui a demanda e a energia consumida, e considera também o horário de ponta, e os períodos seco e úmido, bem como a ultrapassagem de demanda e energia reativa, no caso das tarifas verde e azul. Apesar de haver o reajuste monetário das tarifas de energia elétrica com o tempo, e a diferença de custo nos períodos seco e úmido, fato esse que pode prejudicar uma comparação direta em tempos distintos.

- CEAP - Custo de energia ativa na ponta. Refere-se ao custo de energia elétrica gasta para realizar o trabalho a que se propõem no horário de ponta. Relativo a 3 horas consecutivas entre as $17 \mathrm{~h}$ e $22 \mathrm{~h}$ dependendo da concessionária.

- CEAFP - Custo de energia ativa fora da ponta. Refere-se ao custo de energia elétrica gasta para realizar o trabalho a que se propõem fora do horário de ponta.

- CERP - Custo de energia reativa no horário de ponta. Refere-se ao custo de energia elétrica reativa consumida no horário de ponta. Esse custo é cobrado quando o fator de potência for inferior a 0,92 .

- CERFP - Custo de energia reativa fora da ponta. Refere-se ao custo de energia elétrica reativa consumida fora do horário de ponta.

- CDP - Custo da demanda no horário de ponta. Refere-se ao custo da demanda no horário de ponta.

- CDUP - Custo de ultrapassagem da demanda no horário de ponta. Refere-se a penalidade cobrado pela concessionária relativa a ultrapassagem da demanda contratada no horário de ponta.

- CDFP - Custo da demanda fora do horário de ponta. Refere-se ao custo da demanda fora do horário de ponta.

- CDUFP - Custo de ultrapassagem da demanda fora do horário de ponta. Refere-se a penalidade cobrado pela concessionária relativa a ultrapassagem da demanda contratada fora do horário de ponta.

- CDR - Custo da demanda reativa. Refere-se ao custo da demanda fora do horário de ponta. 
Com os valores das variáveis relativas a estação elevatória de água, os dados serão analisados observando eventuais resultados para os seguintes pontos:

- Adutora ou linha de recalque;

- Bomba hidráulica;

- Motor elétrico;

- Acoplamento Motor - Bomba;

- Operação;

- Custos com energia elétrica.

Separando dessa maneira, facilita a verificação de onde se encontram as maiores perdas.

Com as variáveis, armazenadas em planilhas de cálculo mês a mês durante um período, torna-se possível fazer o acompanhamento e as avaliações como:

- Altura manométrica e perda de carga unitária da tubulação;

- Vazão e volume recalcado;

- A relação entre o volume de água recalcado e a energia consumida em um mês de uso;

- A relação entre o volume de água recalcado e o custo com energia elétrica em um mês;

- A energia reativa, e consequentemente o fator de potência;

- As penalidades tarifárias com a ultrapassagem de demanda;

- O consumo nos horários de ponta e fora do horário de ponta;

- O rendimento do motor frente ao máximo que o fabricante especifica, e o decreto no 4.508 de 11 de dezembro de 2002 menciona, considerando a potência e números de polo em que está ligado;

- O rendimento da bomba considerando os seus limites estabelecidos pelo fabricante e;

- Tempo de operação da elevatória.

Realizar a observação de cada uma destas variáveis, ao longo de um ano na planilha para que se tenha ideia do desempenho da elevatória com relação a energia elétrica, e seus custos que se tem para realizar o trabalho a que se propõem, possibilita ao gestor identificar o que pode ser melhorado para aumentar a eficiência energética e reduzir os custos com energia elétrica da Estação Elevatória de Água Tratada ou Bruta - EEAT ou EEAB.

\section{DISCUSSÃO}

Considerando os elevados custos da energia elétrica, e sua escassez, reduzir o consumo sem reduzir o trabalho executado, passa a ser uma solução necessária e almejada. Nessa linha de raciocínio, esse trabalho, busca obter métricas que avaliem as soluções que indiquem e facilitem a identificação de eventuais falhas ou deficiências no consumo de energia elétrica. A análise das variáveis, balizada em parâmetros estabelecidos nas legislações, nas bibliografias, nos catálogos dos equipamentos, e na prática dos gestores. Possibilita avaliar a eficiência energética de uma estação elevatória de água de forma satisfatória, porém, se essa análise pudesse ser feita com o auxílio de índices de eficiência, ficaria melhor comparar estações elevatórias distintas e com características de vazão e altura manométricas diferentes.

Avaliar a eficiência energética de uma estação elevatória de água em operação é algo complexo, importante, e necessita de vários parâmetros para análise e avaliação. Há situações em que as tubulações tem uma pequena perda de carga unitária, porém o rendimento do conjunto motobomba é baixo frente ao que o motor e a bomba podem alcançar, nesse caso se o gestor somente avaliar a 
adutora, pode fazer com que o resultado da análise seja equivocado, nesse caso concluindo que a estação elevatória de água é eficiente! A proposição do trabalho é justamente que, se faça uma análise de eficiência energética observando todas as variáveis envolvidas no processo, permitindo ao gestor uma análise completa, no que se refere a eficiência energética.

Os próximos passos são: estabelecer relações entre essas variáveis para que o resultado tenha um significado físico da situação; e elaborar um sistema de comparação entre os resultados onde seja possível avaliar o grau de eficiência da unidade que está sendo analisada. Permitindo futuras comparações entre entidades gestoras das cidades no âmbito de iniciativas de aferições métricas ("metric benchmarking");

\section{CONCLUSÃO}

Por meio da revisão de literatura e de visitas técnicas em empresas de saneamento verificou-se que, os gestores dos sistemas têm preocupação em primeiro estágio com o atendimento à demanda. Isto tem razão política, pois o não atendimento trás em rápida velocidade a reclamação da população e a como consequência a imagem da empresa fica desgastada. É evidente que, a continuidade no suprimento de água é algo extremamente necessário, principalmente por razões de saúde pública. Contudo os gestores, em razão de atender os problemas que surgem com urgência, deixam de lado na maioria das vezes de atuar nos problemas que são importantes. A gestão energética de um sistema de abastecimento de água começa a merecer a necessária atenção por dois motivos que são: os elevados custos que passam a comprometer o orçamento das empresas e o risco de não atendimento à demanda.

Analisar o desempenho nas empresas é algo extremamente necessário, e para isso a colaboração por meio de índices de desempenho é provavelmente bem vinda. Contudo, ainda é necessário que se proponha e desenvolva tais índices. Índices estes que possam ser de fácil mensuração e determinação numérica simples. Além disto é preciso realizar estudos sobre referências de satisfação ou insatisfação para os índices. Acredita-se que esteja, por meio deste trabalho, dando partida a uma nova abordagem para se avaliar questões de eficiência energética em sistemas de abastecimento de água.

Assim verifica-se que, são importantes alguns passos, em sequência para a busca da eficiência energética em sistemas de abastecimento de água: o estudo de varáveis que possam compor índices de desempenho; o desenvolvimento de tais índices; a aplicação dos índices em situações reais, a criação de índices de referência para que sejam possíveis as classificações, e finalmente as avaliações. Neste trabalho apresentado estudou-se a primeira etapa, onde discutiu-se a necessidade de criação de índices para a atividade fim, que é a avaliação das variáveis relativas a eficiência energética em estações elevatórias de água.

\section{REFERÊNCIAS}

Alegre, H., BAPtista, J. M., CABRerA, E., Cubillo, F., DuARTe, P., HiRneR, W., MERKEL, W., PARENA, R. Performance Indicators for Water Supply Services: Manual of best practice. 2nd ed. London: IWA Publishing, 2006, 389 p. 
ALMEIDA, A. T.; FERREIRA, F. J. T. E.; BOTH, D.; Technical and Economical Considerations in the Application of Variable-Speed Drives with Electric Motor Systems - IEEE Transactions on Industry Applications Magazine, Vol. 41, no 1, p. 188-199, Janeiro / Fevereiro de 2.005.

ALMEIDA, A. T.; FONSECA, P.; BERTOLDI, P.; Energy-Efficient Motor System in the Industrial and in the Services Sectors in the European Union: Characterisation, Potentials, Barriers and Policies <www.elsevier.com/locate/energy>, Energy no 28, p. 673-690, 2.003.

AMIGO, M. R.; OLIVEIRA, C. D.; Otimização do Consumo de Energia Elétrica Aplicada ao Controle de Vazão de Bombas Centrífugas Radiais - Anais do 3ํ Concurso WEG - Conservação de Energia Elétrica, 2.000.

ANEEL - Agência Nacional de Energia Elétrica, Cadernos Temáticos ANEEL no 4 - Tarifas de Fornecimento de Energia Elétrica, Brasília - DF, Abril de 2.005.

BEN - Balanço Energético Nacional 2015: Ano base 2014 - Empresa de Pesquisa Energética - Rio de Janeiro: EPE, 2015, $292 \mathrm{p}$.

CARVALHO, Paulo S. O. et al. Plano de Gestão Operacional do Sistema de Abastecimento de Água do Campus I da Universidade Federal da Paraíba, com ênfase na Eficiência Energética e Hidráulica. João Pessoa - Paraíba VI SEREA - Seminário Iberoamericano sobre Sistemas de Abastecimento Urbano de Água, 2006. 185 p.

CASSIANO FILHO, A., TSUTIYA, M. T. - Economia nos Custos de Energia Elétrica em Obras Sanitárias Através da Escolha Adequada das Tarifas. Revista DAE, nำ168, p. 8-20, Nov/Dez 1992.

FRANCATO, A. L.; BARBOSA, P. S. FRANCO; NOUR, E. A. A.; A Eficiência Energética na Operação Ótima de Estações Elevatórias de Esgoto. Revista DAE, no185, São Paulo - SP. p. 29-34, Jan 2011.

HAGUIUDA, C., SANTOS NETTO, L. F., e COURA, S. P. - Gestão de Energia Elétrica da SABESP na Região Metropolitana de São Paulo, Racionalização do Uso e Redução dos Gastos. Revista Saneas no9. VII Encontro Técnico AESABESP, São Paulo, Setembro de 1996,

JAMES, $\mathrm{K}$ et al. Água e Energia - Aproveitando as Oportunidades de Eficientização de Água e Energia não Exploradas nos Sistemas Municipais. Aliança para Conservação de Energia. 159p. 2002.

LAMBERT A. International Report on Water Losses Management and Techniques. IWA Conference, Berlin, Alemanha, 2001.

OLIVEIRA JR., N.; Acionamento de Corrente Alternada de Velocidade/Frequência Variáveis - Catálogo de Fabricante, Abril de 1.993.

PROCEL - Programa Nacional de Conservação de Energia Elétrica. Relatório de Resultados PROCEL 2014 - Ano base 2013 - 2014. Brasília - DF, 2014. 147p.

SÁ, André Fernando Ribeiro de. Guia de aplicações de gestão de energia e eficiência energética, 2ạ Edição. Porto - Portugal - Publindustria, 2010. 461 p. 
SNIS - Sistema Nacional de Informações sobre Saneamento. Diagnóstico dos Serviços de Água e Esgotos 2013. Brasília - DF: SNSA/MCIDADES, 2014. 181p.

TSUTIYA, Milton Tomoyuki. Redução do custo de energia elétrica em Estações Elevatórias de Sistemas de Abastecimento de Água de Pequeno e Médio Portes. Tese de Doutoramento. Escola Politécnica da USP. São Paulo, 1989.

TSUTIYA, Milton Tomoyuki. Redução do custo de energia elétrica em sistemas de abastecimento de água. 1ạ Edição. São Paulo - Associação Brasileira de Engenharia Sanitária e Ambiental, 2006. 185 p.

ZESSLER, U.; SHAMIR, U.; Optimal Operation of Water Distribution Systems - Journal of Water Resources Planning and Management $n^{\circ}$ 6, Vol. 115, p. 735-751, 1.989. 